\title{
Experimental Investigation of Loop Heat Pipe with Two Evaporators/Two Condensers under Thermal Vacuum Condition
}

\author{
Xinyu Chang, Hosei Nagano \\ Department of Aero-Space Engineering, Nagoya University, Nagoya, Japan \\ Email: chang@prop2.nuae.nagoya-u.ac.jp
}

Received 14 June 2016; accepted 8 August 2016; published 15 August 2016

\begin{abstract}
Multiple loop heat pipe is a high-functional thermal transport device. This work was conducted to confirm the working performance of Multiple loop heat pipe under thermal vacuum ambience with the working fluid ammonia. Asmall multiple loop heat pipe with two evaporators and two radiators was designed and fabricated. Then thermal vacuum test was conducted. The heaters were fasten on both evaporators, both radiators, both compensation chambers. In the case that both evaporators were heated, the multiple loop heat pipe can transport $120 / 120 \mathrm{~W}$ for $1.5 \mathrm{~m}$, in the case that only one evaporator was heated, evaporator 1 can transport $80 \mathrm{~W}$ for $1.5 \mathrm{~m}$, while evaporator 2 can transport $120 \mathrm{~W}$ for $1.5 \mathrm{~m}$. Two flow regulators were installed near the confluence of liquid line to prevent uncondensed vapor penetrating into returning liquid when the temperature difference exists between two radiators. In the case that the heat load at both evaporators were $40 / 40 \mathrm{~W}$ and one radiator was heated, the flow regulator1 can tolerate the $160 \mathrm{~W}$ of heat load which was supplied to radiator 1 while the flow regulator2 can tolerate the $100 \mathrm{~W}$ of heat load which was supplied to radiator2. To demonstrate the multiple loop heat pipe's startup behavior at lowheat load, each of the compensation chamber was preheated to change the initial distribution of liquid and vapor in the evaporator and compensation chamber, in the result, each evaporator can start up at $5 \mathrm{~W}$ through preheating.
\end{abstract}

\section{Keywords}

Loop Heat Pipe, Ammonia, Thermal Vacuum Test, Two Phase Flow

\section{Introduction}

Loop heat pipe (LHP) is a robust thermal transfer device for cooling electronic components [1]. Figure 1 shows the schematic of LHP. A LHP consists of one evaporator (Evap), one vapor line (VL), one condenser (Cond), one liquid line (LL), one compensation chamber (CC) and one primary wick (PW).

How to cite this paper: Chang, X.Y. and Nagano, H. (2016) Experimental Investigation of Loop Heat Pipe with Two Evaporators/Two Condensers under Thermal Vacuum Condition. Journal of Applied Mathematics and Physics, 4, 1460-1469. 

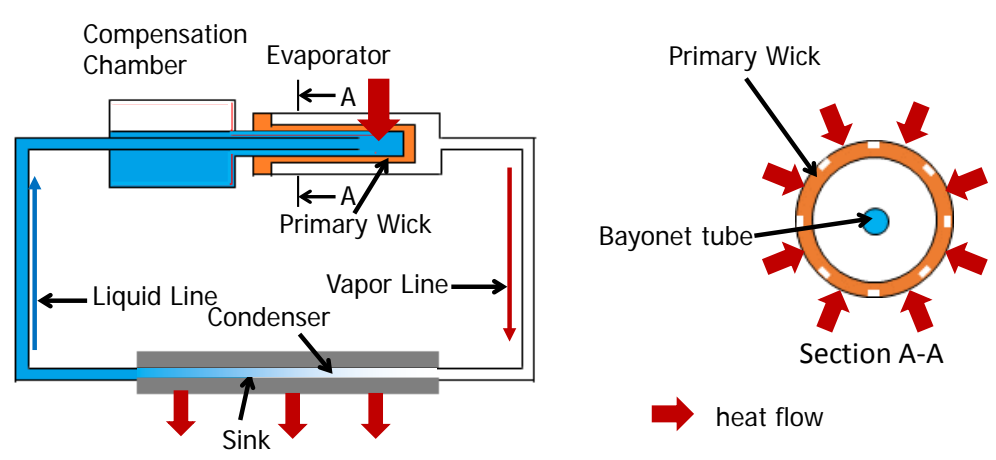

Figure 1. Schematic of LHP.

The LHP employed the capillary force which generates in the porous structure to drive the inner working fluid. With the circulation and phase change of working fluid, the heat can be transported from evaporator (receiving heat from operating machine) to condenser (dissipating heat to outside, which is often embedded into radiator).Compared with conventional heat transfer device, LHP is free of electricity and can transfer more heat with longer distance. With its merits, the LHP has been applied in several spaceships [2]. Multiple loop heat pipe (MLHP) is a kind of LHP which has multiple evaporators and multiple condensers, it has been demonstrated in the year 1997 [3]. The mathematical models has been established in the year 2004, 2005 [4] [5].

The MLHP has not been utilized as a thermal control device for spaceships because the operating characteristics have not been totally confirmed. According to the literature, the related research is rare. Only one experiment on investigation was developed in America [6]. This research aims to demonstrate and figure out the operating performance of MLHP. In this research, firstly, a MLHP with two evaporators and two condensers for space demonstration was designed and fabricated. Then the thermal vacuum test was carried out to figure out the operating performance of MLHP with working fluid ammonia under the case that both evaporators were heated/one evaporator was heated and bothradiators were operated with the same heat load. The tests to confirm the performance of flow regulator (FR, a device to regulate the mass flow rate at each condenser side in the case that the temperature difference exists between two radiators. with ultra-high weight molecular (UHWM) polyethylene porous structure were also conducted under the case that both evaporators were employed with the constant heat load and one condenser was heated by flexible heater. The tests to demonstrate the startup behavior at low heat load $(5 \mathrm{~W})$ with preheating were carried out under the case that one evaporator was heated with $5 \mathrm{~W}$ and each radiator was heated with 60W to keep warm.

\section{Operating Principle of Multiple Loop Heat Pipe}

Figure 2 shows the schematic of MLHP. Compared with LHP, MLHP has two operating patterns. The Figure 2(a) shows the case that two evaporators are heated. In this case, the MLHP operates like LHP, the heat was absorbed from working machine to evaporators, then the evaporation happens and the vapor was generated. The vapor flows through the vapor line then condenses in the condenser and dissipates the heat to outside. Finally, the condensed working fluid flows back to evaporator, replenishing the evaporation volume. Since the MLHP has several evaporators, it can cool several heat sources or a heat source with large footprint. Figure 2(b) shows the case that one evaporator is heated. In this case, the flowing direction of working fluid in the unemployed evaporator is inversed, making the un-employed evaporator work as a condenser. In this way, the operating evaporator can provide the heat to unemployed evaporator, keeping the unemployed evaporator warm. The MLHP has two condensers. Therefore, compared with LHP, MLHP can operate in the case that one radiator`s temperature is too high to diffuse the heat, by diffusing the heat through the other radiator In this case, the flow regulator becomes necessary.

Figure 3 shows the schematic of flow regulator, there is a porous structure in flow regulator, the porous structure can only permit liquid to flow through. Therefore, the uncondensed vapor which flows through the high temperature condenser side is blocked and diverted to low temperature side. In this way, more working fluid can flow through the low temperature condenser side, making the low temperature condenser fully utilized and reducing the temperature of returning liquid, which can make the whole loop operate at lower temperature. Equation (1) shows the flow regulator's operating condition. 


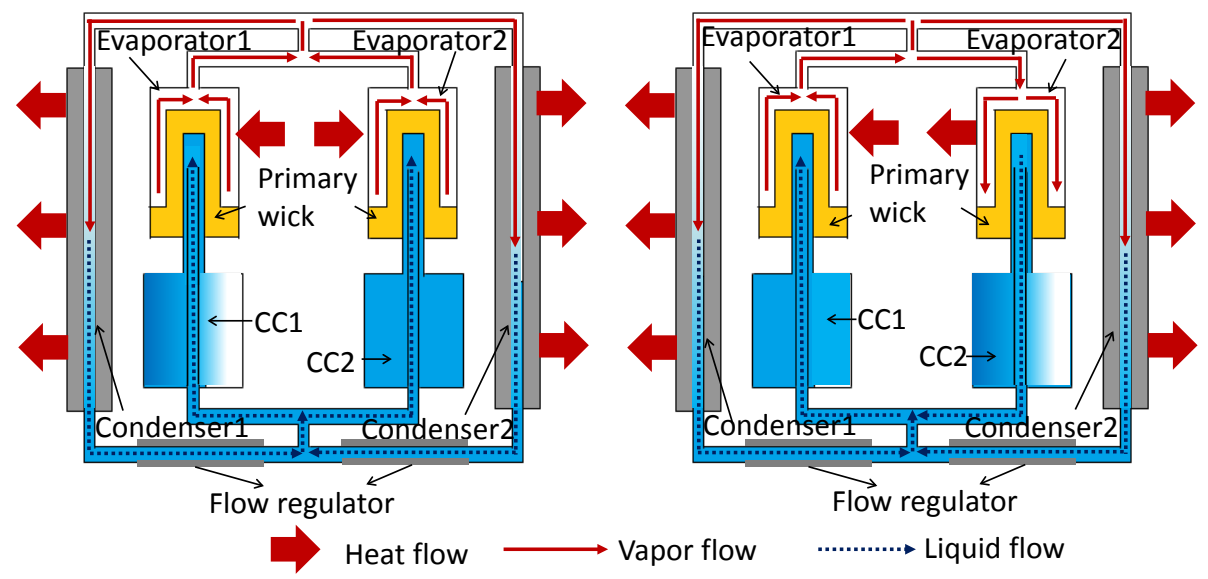

(a)

(b)

Figure 2. Schematic of MLHP. (a) Both evaporators are employed; (b) One evaporator is employed.

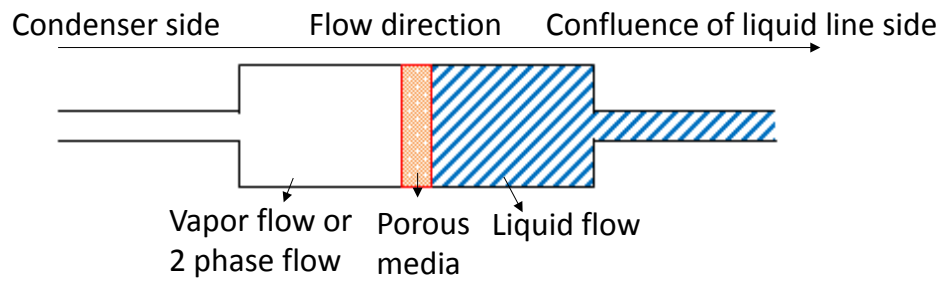

Figure 3. Schematic of flow regulator.

$$
P_{\text {cap }}=P_{v l_{-} l l}+P_{F R}
$$

The $P_{\text {cap }}$ presents the capillary force of the porous structure, the $P_{v l} l l$ presents the pressure loss from the diverging point of common vapor line to the confluence of common liquid line (except the pressure loss which is generated when working fluid flows through the flow regulator) and the $P_{F R}$ presents the pressure loss generated by porous structure in flow regulator.

\section{Multiple Loop Heat Pipe Equipment and Test Conditions}

Table 1 presents the configurations of MLHP, the MLHP is designed to transport $260 \mathrm{~W}$ in total (130 W/evaporator) for $1.5 \mathrm{~m}$. The primary wick was made of stainless steel and the flow regulator's porous structure was made of UHWM polyethylene. In the thermal vacuum test, the MLHP was wrapped with Multi-layer insulation (MLI) material except the radiation side of radiator. Each condenser was embedded into the radiator in order to enhance the heat diffusing ability. Both radiators were painted black with Z306 flat black to improve the emissivity. The flexible heaters with the size of $30 \mathrm{~cm} \times 30 \mathrm{~cm}$ were pasted on the center each radiator to keep the radiator warm when MLHP operated at low temperature and to simulate the heat from sunlight.

Figure 4 shows the position of thermocouples (TC) and Figure 5 presents the photo of MLHP. In this experiment, the ammonia was applied as working fluid, 53 thermocouples were employed to measure the temperature of MLHP equipment. The thermal vacuum chamber was kept under $-180^{\circ} \mathrm{C}$ and $10^{-5} \mathrm{~Pa}$.

Table 2 shows the experiment conditions. The heat loads with each evaporator and radiator are shown respect tively. The test 1 was conducted to demonstrate the operation of MLHP and measure the largest heat transport capability figure out the heat transfer ability of MLHP with the working fluid ammonia. The test 2 was carried out to confirm the heat transfer ability of each evaporator and demonstrate the heat exchange between two evaporators. The test 3 was conducted to demonstrate the operation of flow regulator with UHMW polyethylene. The test 4 was carried out to demonstrate the startup behavior of MLHP at low heat load with preheating. The tests were stopped when the MLHP reached its capillary limit or the temperature of any component rose above $70^{\circ} \mathrm{C}$. 

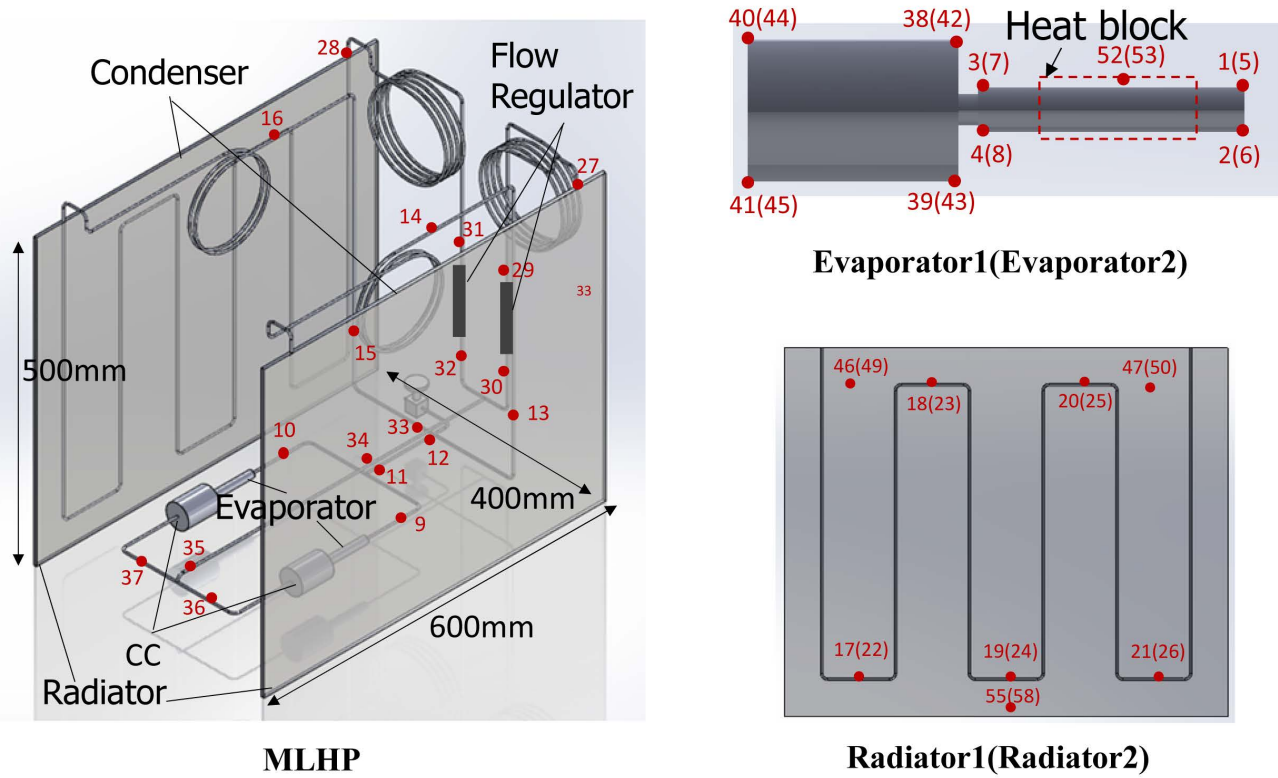

Evaporator1(Evaporator2)

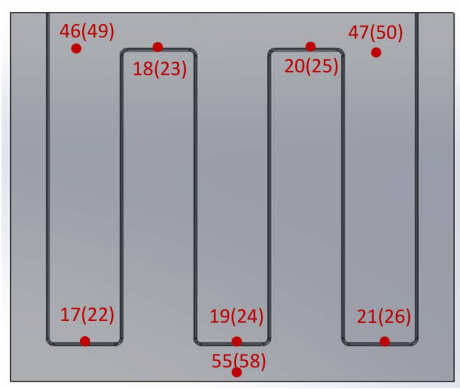

Radiator1(Radiator2)

Figure 4. Thermocouples’ position.

Table 1. Configurations of MLHP.

\begin{tabular}{|c|c|c|c|}
\hline \multicolumn{2}{|c|}{ Evaporator } & \multicolumn{2}{|c|}{ Compensation Chamber } \\
\hline Length [mm] & 59 & Length $[\mathrm{mm}]$ & 55 \\
\hline Inner Diameter [mm] & 10 & Inner Diameter [mm] & 37 \\
\hline \multicolumn{2}{|c|}{ Vapor Line/Liquid Line } & \multicolumn{2}{|c|}{ Radiator } \\
\hline Length $[\mathrm{mm}]$ & $1960 / 2455$ & Length $[\mathrm{mm}]$ & 600 \\
\hline Inner Diameter [mm] & 1.75 & Width [mm] & 500 \\
\hline \multicolumn{2}{|c|}{ Condenser } & Thickness [mm] & 6 \\
\hline Length [mm] & 3000 & \multicolumn{2}{|c|}{ Primary Wick } \\
\hline Inner Diameter [mm] & 1.75 & Material & Stainless Steel \\
\hline \multicolumn{2}{|c|}{ Pore Structure for Flow Regulator } & Length $[\mathrm{mm}]$ & 50 \\
\hline Material & UHMW polyethylene porous & Outer Diameter [mm] & 10 \\
\hline Thickness [mm] & 1 & Inner Diameter [mm] & 7 \\
\hline Diameter [mm] & 10 & Pore Radius $[\mu \mathrm{m}]$ & $3.7 / 3.4$ \\
\hline Pore Radius $[\mu \mathrm{m}]$ & 5 & & \\
\hline
\end{tabular}

Table 2. Experimental conditions.

\begin{tabular}{ccc}
\hline & \multicolumn{2}{c}{ Heat load [W] } \\
\cline { 2 - 3 } Test 1 & Evaportor $1 /$ Evaporator 2 & Radiator $1 /$ Radiator 2 \\
\multirow{2}{*}{ Test 2} & $40 / 40,60 / 60,80 / 80,100 / 100,110 / 110,120 / 120$ & $0 / 0$ \\
& $40 / 0,60 / 0,80 / 0,100 / 0,110 / 0,120 / 0$ & $40 / 40,30,30,20 / 20,10 / 10,0 / 0$ \\
Test 3 & $0 / 40,0 / 60,0 / 80,0 / 100,0 / 110,0 / 120$ & $40 / 40,30,30,20 / 20,10 / 10,0 / 0$ \\
& $40 / 40$ & $40 / 0,80 / 0,100 / 0,120 / 0,160 / 0$ \\
Test 4 & $40 / 40$ & $0 / 40,0 / 60,0 / 80,0 / 100,0 / 120$ \\
& $5 / 0$ & $60 / 60$ \\
\hline
\end{tabular}




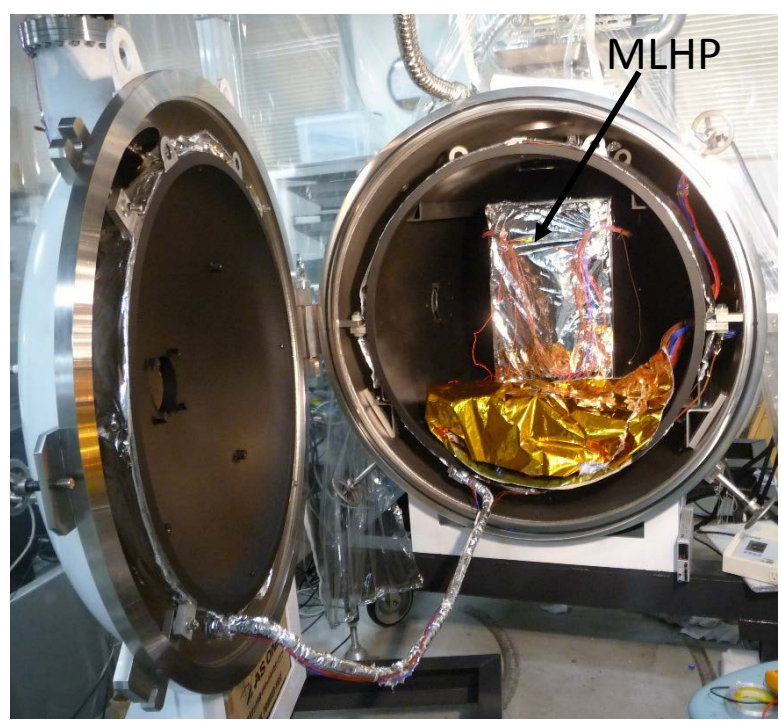

Figure 5. Photo of MLHP.

\section{Test Result}

\subsection{Test Result of Case 1}

Figure 6 shows the steady state behavior of MLHP under the condition that two evaporators were heated and two condensers were operated without heat loads. The x-axis shows the heat loads and the y-axis presents the temperature of evaporator and compensation chamber at each heat load. Judging from the Figure 6, the MLHP can transport $240 \mathrm{~W}$ in total (120W/evaporator) for $1.5 \mathrm{~m}$. Therefore, the operation of MLHP was demonstrated. The calculations was done in the case that two evaporators' temperature were 100/100 W, 110/110 W, 120/120 W. It can be inferred that the calculations agrees well with the test results. The MLHP's heat transport ability was not attainted the designing goals $(130 / 130 \mathrm{~W})$. The reason is that with the rising of heat loads, the temperature rose and deteriorated the adhesives between heat blocks and evaporators. When the heat loads rose to $130 / 130 \mathrm{~W}$, the heat block1's temperature rose above $200^{\circ} \mathrm{C}$ and the evaporator 1 's temperature rose above $70^{\circ} \mathrm{C}$, then the experiment was stopped. According to the test result, the thermal conductance between evaporator1 and heat block1 at $80 / 80 \mathrm{~W}, 100 / 100 \mathrm{~W}, 110 / 110 \mathrm{~W}$ and $120 / 120 \mathrm{~W}$ were $884 \mathrm{~W} /{ }^{\circ} \mathrm{C}, 818 \mathrm{~W} /{ }^{\circ} \mathrm{C}, 831 \mathrm{~W} /{ }^{\circ} \mathrm{C}, 609$ $\mathrm{W} /{ }^{\circ} \mathrm{C}$, respectively. Therefore, it can be found that when the heat loads rose to $120 / 120 \mathrm{~W}$, the adhesive strength of adhesives began to deteriorate. To avoid this problem, in the future research, the adhesives which can tolerate high temperature will be utilized.

\subsection{Test Result of Case 2}

Figure 7 shows the steady state performance of MLHP under the condition that only evaporator 2 was heated. The $\mathrm{x}$-axis shows the heat load, the left $\mathrm{y}$-axis presents the temperature of evaporator and compensation chamber at each heat load and the right $\mathrm{y}$-axis presents the heat loads at two radiators which were used to keep warm. Because of the deterioration of adhesive at high temperature, the experiment was continued until the heat load at evaporator 2 side rose to $120 \mathrm{~W}$. The calculations on the temperature of each evaporator and compensation chamber were conducted respectively. Judging from the Figure 7, it can be found that the temperature of evaporator and compensation chamber was well predicted. In the calculations, the MLI was supposed to insulate the heat totally between MLHP and thermal vacuum ambience. However, there existed the radiation to outside actually. As the result, the unemployed evaporator needs the heat from employed evaporator to keep warm. The heat exchange volume can be evaluated through Equation (2). The $T_{\text {in }}$ presents the temperature at the inlet of unemployed evaporator (Thermocouple 9), the $\overline{T_{e v}}$ presents the average temperature of unemployed evaporator. The denominator at the right side of the equal sign presents the heat resistance from the porous structure to the inner wall of evaporator and the heat resistance between the evaporator case. The $h_{\text {evap }}$ presents the thermal transfer coefficient between the stainless steel primary wick to the inner wall of evaporator. 


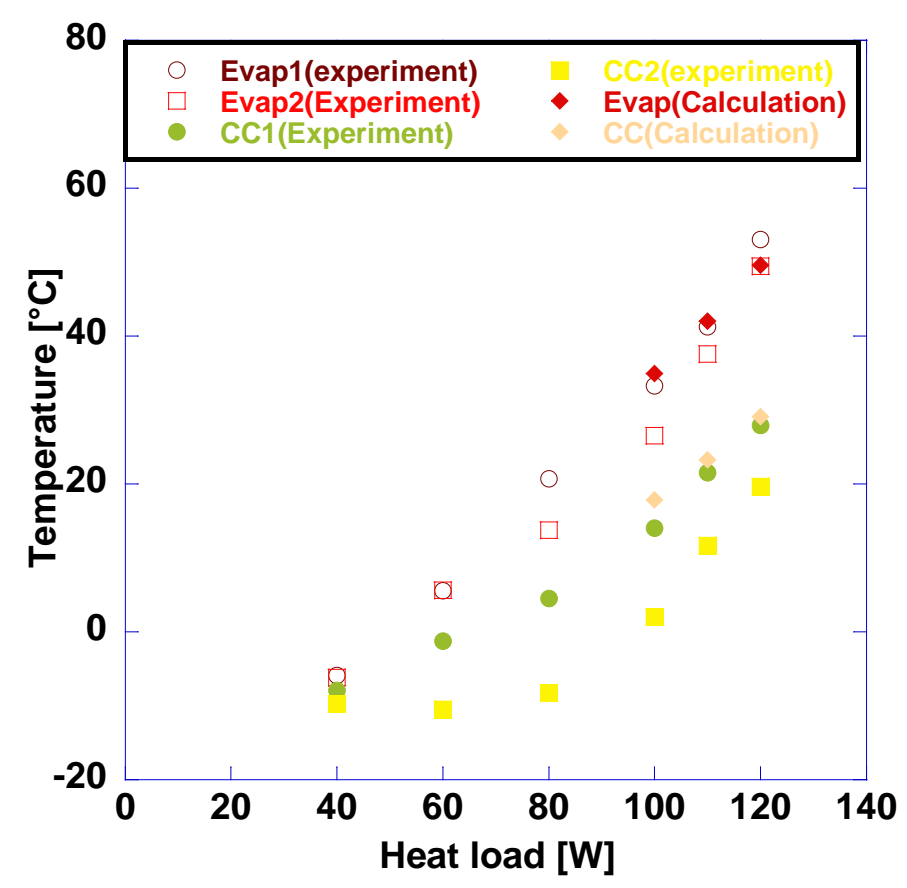

Figure 6. Temperature at steady state of test 1.

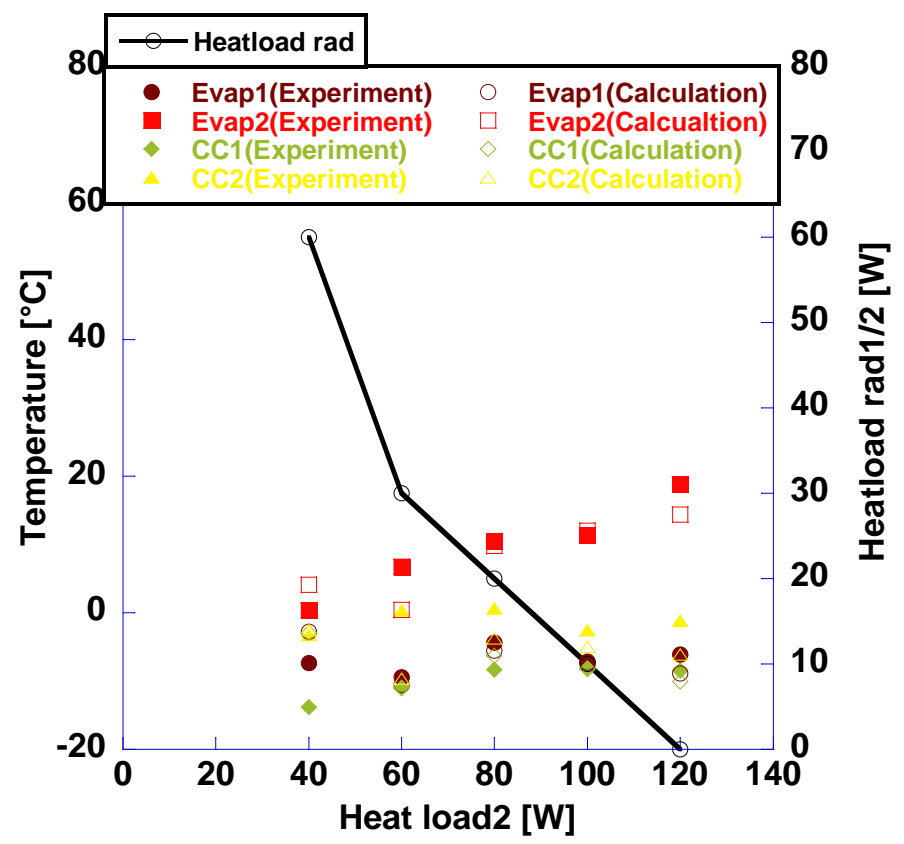

Figure 7. Temperature at steady state of test 2.

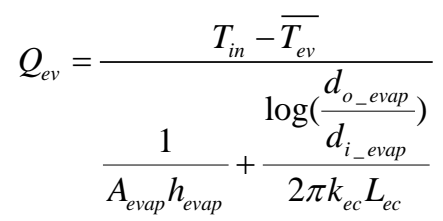

According to the Equation (2), assuming that the $h_{\text {evap }}$ was $350 \mathrm{~W} / \mathrm{m}^{2}$, the heat exchange amount was about 
$3 \mathrm{~W}$ when the heat load on evaporator 2 varied from $60 \mathrm{~W}$ to $120 \mathrm{~W}$. The heat exchange amount will rise if the MLI at unemployed evaporator is removed. The test that only evaporator 1 was heated showed the same operating characteristics unless the largest heat transfer value became to $80 \mathrm{~W}$ because of the deterioration of adhesives.

\subsection{Test Result of Case 3}

Figure 8 shows the temperature profile of the MLHP under the condition that the heat loads at both evaporators' side were kept at 40/40W and the radiator 1 was heated. Figure 9 shows the detailed temperature profile of thermocouples those were pasted near flow regulator. The x-axis shows the time, the left y-axis shows the temperature and the right $y$-axis presents the heat load at two radiators. The steady state temperature of the entrance and exit of each flow regulator (FR1: TC29, TC30; FR2: TC31, TC32) and the steady state temperature of the liquid line`s confluence (TC 35) with the variation of heat load at radiator 2 was shown at Table 3.

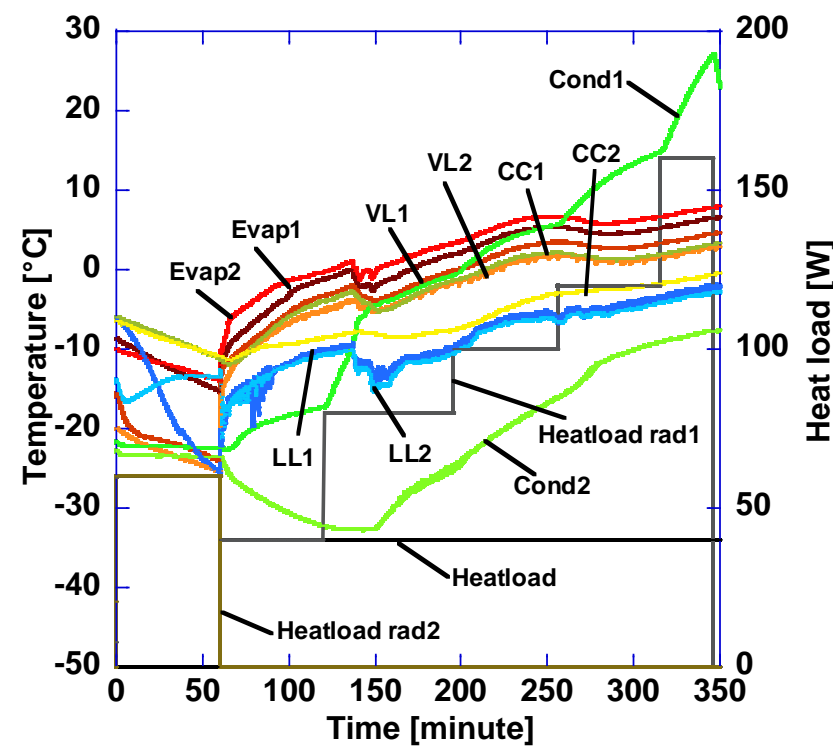

Figure 8. Temperature profile of test 3 (MLHP).

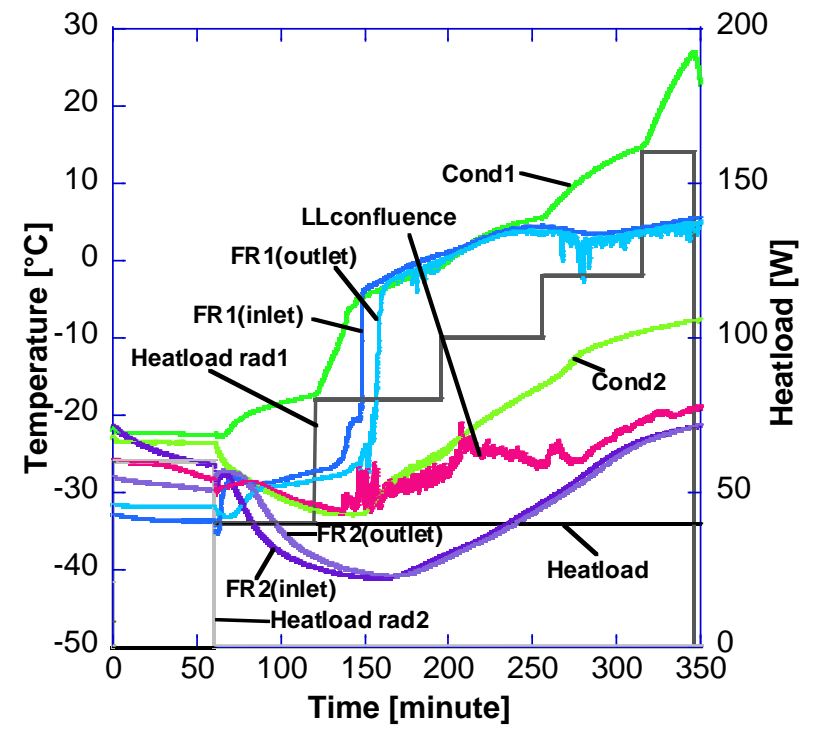

Figure 9. Temperature profile of test 3 (FR). 
Table 3. Steady state temperature of flow regulator component.

\begin{tabular}{ccccccc}
\hline & \multicolumn{5}{c}{ Temperature $\left[{ }^{\circ} \mathrm{C}\right]$} \\
\hline & & FR 1 Entrance & FR 1 Exit & FR 2 Entrance & FR 2 exit & LL confluence \\
& 40 & -27.2 & -28.3 & -39.6 & -38.3 & -31.6 \\
Heat load & 80 & 0.83 & 0.05 & -38.2 & -38.8 & -27.4 \\
$\begin{array}{c}\text { at radiator } 2 \\
{[\text { W] }}\end{array}$ & 100 & 4.5 & 4.0 & -31.3 & -32.0 & -26.4 \\
& 120 & 4.3 & 3.8 & -23.2 & -23.6 & -20.8 \\
& 160 & 5.5 & 4.7 & -21.5 & -21.5 & -19.2 \\
\hline
\end{tabular}

Judging from the Table 3, when the heat load at radiator 1 was $40 \mathrm{~W}$, the temperature of liquid line confluence was close to the FR1, which shows that the all the vapor was condensed in the condenser. When the heat load kept rising, the temperature of liquid line`s confluence began to close to the FR2, which indicated the flow regulator 1 operated and prevented the high temperature vapor, which makes more and more working fluid flows through the unpowered radiator. Since the temperature of liquid line's confluence was not risen sharply and was kept close to the FR2's temperature, the operating characteristics of FR in this MLHP was demonstrated. From the calculation, in the case that the heat load on the radiator 2 was $160 \mathrm{~W}$, the pressure loss from the diverging point of vapor line to the confluence of liquid line was $4047 \mathrm{~Pa}$. The contact angle at the FR 1 was $75.6^{\circ}$, which can be calculated by Equation (3).

$$
\cos \theta=\frac{P_{v l_{-l l}} R_{\text {pore }}}{2 \sigma}
$$

In the case that the radiator 2 was heated, the FR2 was operated in the same method. However, the FR2 can only tolerate $100 \mathrm{~W}$ heat load which was supplied to radiator2. One of the probable reason is that the sealability between the FR2's porous structure and the inner wall of FR2 was not good.

\subsection{Test Result of Case 4}

When the temperature difference between evaporator and compensation chamber reaches a certain value (superheat), the bubble generates into the evaporator and the MLHP begins to operate. It is difficult for a MLHP to start up at low heat load because the heat leak from the evaporator to compensation chamber is high, which makes the superheat cannot be attained. To improve the startup behavior at low heat load, the compensation chamber was preheated to change the distribution of working fluid, which can transport the liquid from compensation chamber to the core of primary wick and reduce the heat leak. Figure $\mathbf{1 0}$ shows the temperature profile of the MLHP under the condition that the MLHP started at low heat load (5 W) at evaporator2without preheating at compensation chamber 2 . The $\mathrm{x}$-axis shows the time while $y$-axis presents the temperature. Figure 11 shows the temperature profile of the MLHP under the condition that the MLHP started at low heat load (5 W) at evaporator2 with preheating at compensation chamber 2. The $\mathrm{x}$-axis shows the time while left $\mathrm{y}$-axis presents the temperature. The right y-axis shows the heat load of preheating. The test without preheating was continued 20 minutes. In the test period, the temperature of vapor line did not increase, therefore, the MLHP cannot startup. While in the case with preheating compensation chamber at $2 \mathrm{~W}$ for 4 minutes, the MLHP started up 5 minutes later when the temperature of vapor line2 began to increase. The vapor reached the inlet of condenser1 $31 \mathrm{mi}$ nutes later from the startup. The MLHP operated in steady state at 50 minutes after the startup. Therefore, the startup behavior at $5 \mathrm{~W}$ was demonstrated with preheating on compensation chamber. The preheating experiment at evaporator1 and compensation chamber1 was carried out too and showed the same result with the preheating experiment at evaporator2 and compensation chamber 2.

\section{Conclusion}

In this research, the operating characteristic of MLHP under thermal vacuum condition was experimentally investigated. In the case that both evaporators were employed, the MLHP was demonstrated and can operate stably, transporting $240 \mathrm{~W}$ in total for $1.5 \mathrm{~m}$. In the case that one evaporator was employed, the heat exchange be- 


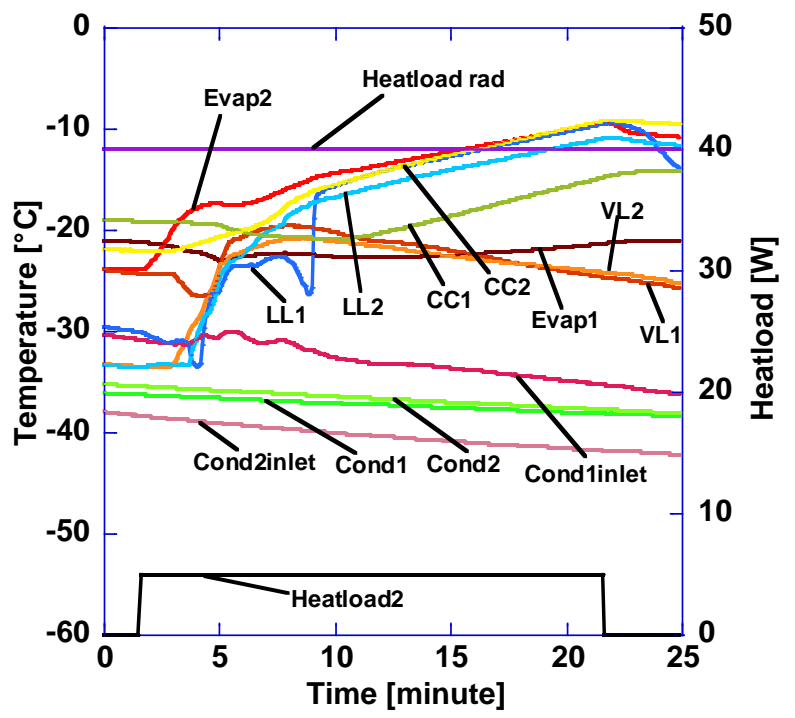

Figure 10. Temperature profile of test 4 (without preheated).

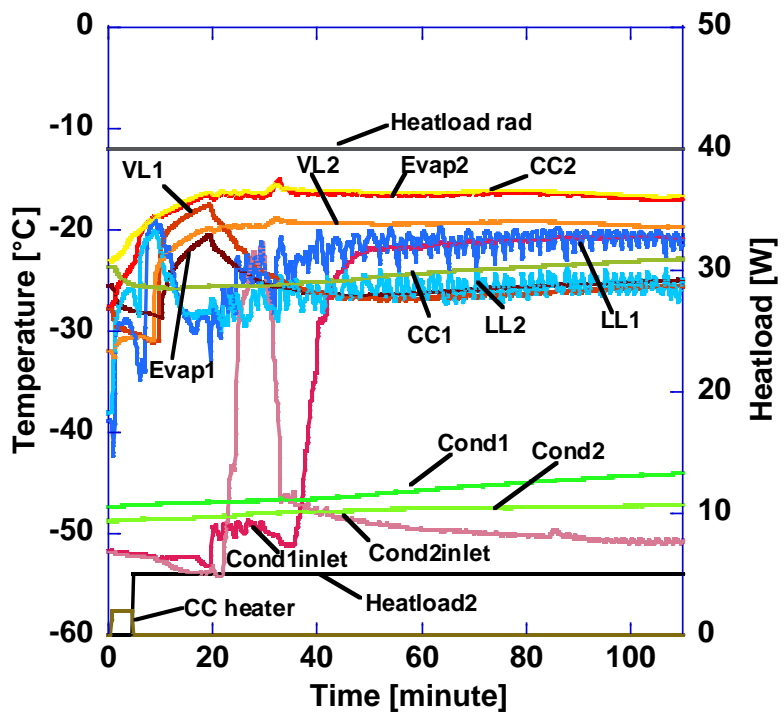

Figure 11. Temperature profile of test 4 (preheated).

tween two evaporators was confirmed. The tests with the temperature difference between two radiators were conducted and the working performance of flow regulators were evaluated. The startup behavior at low heat load with preheating compensation chamber was demonstrated.

\section{Acknowledgements}

This research is partially supported by H. Ogawa, S. Okazaki from ISAS, H. Nagai from TOHOKU University. The author would like to express his sincere thanks to them.

\section{References}

[1] Ku, J. (1999) Operating Characteristics of Loop Heat Pipes. Proceeding of $29^{\text {th }}$ International Conference on Environmental System, Denver, 12-15 July 1999. http://dx.doi.org/10.4271/1999-01-2007

[2] Baker, C., McCarthy, T. and Grob, E. (2004) Geoscience Laser Altimeter System (Glas) Loop Heat Pipes-An Eventful First Year On-Orbit. Proceeding of $34^{\text {th }}$ International Conference on Environmental Systems, Colorado Springs, 
18-22 July 2004.

[3] Bienert, W.B., et al. (1997) The Proof-of-Feasibility of Multiple Evaporator Loop Heat Pipes. Proceedings of the Sixth European Symposium on Space Environmental Control Systems, Noordwijk, 20-22 May 1997, 393-398.

[4] Hoang, T.T. and Ku, J. (2004) Mathematical Modeling of Loop Heat Pipes with Multiple Capillary Pumps and Multiple Condensers Part I-Steady State Simulations. Proceedings of the AIAA, 2nd International Energy Conversion Engineering Conference, Providence, 16-19 August 2004.

[5] Hoang, T.T. and Ku, J. (2005) Mathematical Modeling of Loop Heat Pipes with Multiple Evaporators and Multiple Condensers. Proceedings of the 3rd International Energy Conversion Engineering Conference, San Francisco, 15-18 August 2005. http://dx.doi.org/10.2514/6.2005-5682

[6] Ku, J., Ottenstein, L. and Douglas, D. (2008) Multiple-Evaporator Miniature Loop Heat Pipe for Small Spacecraft Thermal Control. Proceedings of the $49^{\text {th }}$ AIAA/ASME/ASCE/AHS/ASC Structures, Structural Dynamics, and Materials Conference, Schaumburg, 7-10 April 2008.

Submit or recommend next manuscript to SCIRP and we will provide best service for you:

Accepting pre-submission inquiries through Email, Facebook, LinkedIn, Twitter, etc.

A wide selection of journals (inclusive of 9 subjects, more than 200 journals)

Providing 24-hour high-quality service

User-friendly online submission system

Fair and swift peer-review system

Efficient typesetting and proofreading procedure

Display of the result of downloads and visits, as well as the number of cited articles

Maximum dissemination of your research work

Submit your manuscript at: http://papersubmission.scirp.org/ 